Revista de la red interuniversitaria de estudios sobre las literaturas rioplatenses contemporáneas en Francia

$10 \mid 2014$

El XIX en el XX

\title{
Baudelaire, amigo de Rivera
}

Iván Jiménez

URL: http://journals.openedition.org/lirico/1707

DOI: $10.4000 /$ lirico. 1707

ISSN: 2262-8339

Editor

Réseau interuniversitaire d'étude des littératures contemporaines du Río de la Plata

Referencia electrónica

Iván Jiménez, «Baudelaire, amigo de Rivera », Cuadernos LIRICO [En línea], 10 | 2014, Puesto en línea el

01 marzo 2014, consultado el 20 abril 2019. URL : http://journals.openedition.org/lirico/1707 ; DOI :

10.4000/lirico.1707

Este documento fue generado automáticamente el 20 abril 2019.

\section{(c) $(1) \Theta \Theta$}

Cuadernos LIRICO está distribuido bajo una Licencia Creative Commons Atribución-NoComercialSinDerivar 4.0 Internacional. 


\title{
Baudelaire, amigo de Rivera
}

\author{
Iván Jiménez
}

1 El amigo de Baudelaire, la novela que Andrés Rivera publica en 1991, nos sitúa en las últimas décadas del siglo XIX mediante la narración de Saúl Bedoya, un personaje que representa la hegemonía de la clase burguesa en el momento de la consolidación del modelo republicano para el país argentino. Este juez terrateniente, hijo de un gaucho y educado en París, desarrolla, como otros hombres de su siglo, una escritura autobiográfica en la que medita sobre su vida y su época. En su monólogo, Bedoya quisiera alcanzar una escritura alejada del utilitarismo y de las transacciones mercantiles que imperan en su mundo: "Me atengo a una sola ley, afirma : no hay comercio entre lo que escribo y yo. Nadie vende, nadie miente. Nadie compra, nadie es engañado" (Rivera 1991 9). Las intimidades que Bedoya relata de manera discontinua son yuxtapuestas a microrelatos en los que la historia política argentina es relacionada con la historia de la literatura francesa. Al imaginar este mundo posible a partir de los saberes sobre el pasado, la novela de Rivera dota a este burgués de pensamientos obsesivos sobre Charles Baudelaire y Domingo Faustino Sarmiento. Cecilia Pozzo explica el cruce imaginario de estas tres figuras diciendo que "un personaje de ficción tiende un puente entre dos personajes históricos polarizados y centra en la intimidad de sus cuadernos la tensión de un encuentro no expuesto por la historia" (Pozzo 37).

2 La crítica de los 90 señala la relación especular de rivalidad que vincula a Bedoya con Baudelaire y con Sarmiento. Susana López (51) define a Bedoya como un burgués que "envidia la literatura ajena" y que gracias a su "impregnación cultural europea" (50) toma al poeta francés como un "ideal estético y vital" (48); también observa que Sarmiento, visto como un "provinciano pobre, autodidacta y viejo", es un "antagonista" para el "pragmático" Bedoya y que este juez - "porteño, dandy y distinguido" - representa todo lo que el presidente "hubiera querido ser" $(51,52)$. Según Pozzo (36), Bedoya escribe "la otra cara de la historia": "un contra-diario de viajes al ascético Sarmiento". Tales observaciones dan cuenta del modo en que la crítica de los 90 considera las relaciones entre ficción e historia. En primera instancia, insiste en el gesto crítico o desacralizador de la ficción con respecto a la historiografía positivista del siglo XIX y a su concepto de 
verdad sobre los hechos. Hay también un énfasis en el narrador en primera persona, recurso formal al que se atribuye un doble efecto político: por un lado, recuperar la diversidad de significaciones sobre el pasado que aporta la memoria (Id. 33) ; por el otro, tener en cuenta la subjetividad para mostrar la historia como un proceso que "se vive" ( Id. 37). Para Pozzo (39), la "voz" de Bedoya "logra el acercamiento más íntimo entre el narrador y el personaje, la primera persona de un memorialista que vuelca sus subjetividades acerca de la historia. Una vida particular que ejemplifi[ca] 'negativamente' el discurso de la Historia".

3 Sin pretender negar el alcance explicativo de tales observaciones, quisiéramos señalar que presuponen una idea bastante arraigada en los estudios literarios, idea que en nuestra opinión resulta hoy problemática. Con frecuencia, los estudios críticos plantean una especie de enemistad fundamental entre el discurso literario y el discurso histórico, y esto nos lleva a creer, tácita o explícitamente, que la disciplina histórica aspira a "restituir las cosas tal como sucedieron" y que las novelas históricas introducen "subjetividad" allí donde los historiadores han querido hacer reinar la "objetividad". Y por eso se insiste tanto en tomar al positivismo historiográfico heredado del siglo XIX como paradigma representativo de toda la labor de los historiadores. Martín Kohan (1091) ha estudiado este "malentendido" epistemológico en el caso de algunas obras narrativas que se han trazado el dudoso propósito de "humanizar" al "deshumanizado" Libertador José de San Martín. Desde el ámbito de la filosofía, hace más de sesenta años, Paul Ricoeur (1952) había aclarado que hay una subjetividad que interviene en la labor del historiador (1990 38) ${ }^{1}$, y que cuando éste aplica el principio de objetividad en su metodología, no busca necesariamente imponer como verdad absoluta un conjunto de huellas del pasado, sino al contrario, construir un campo de observación que le permita establecer distanciamientos y acercamientos (35) con respecto a esas huellas (Id. 30) ${ }^{2}$. El mismo Ricoeur, siempre atento a las zonas de vecindad ("voisinage") entre la historia y la ficción, en un estudio preliminar (1980 67) a Temps et récit, explica ${ }^{3}$ que cuando el historiador elabora sus hipótesis sobre la realidad del pasado, pasa necesariamente por el juego con los posibles propio de la ficción. Más recientemente, el historiador François Hartog, conocido por su teoría sobre el presentismo (2012), es decir, la supremacía que han adquirido el presente y lo inmediato como horizontes de la acción humana, también se ha dado a la tarea de pensar los contornos de la labor del historiador; su reflexión se inscribe en este momento en el que priman las visiones a corto plazo - en lo económico, lo político y lo cultural - y los imperativos reparadores de la memoria ; también toma en cuenta los múltiples cuestionamientos hacia la historia por parte del pensamiento posmoderno de las cuatro últimas décadas. En Croire en l'histoire (2013), libro que contiene un extenso capítulo sobre los modos en que los novelistas trabajan con el pasado histórico, Hartog formula los siguientes interrogantes :

Quel est le rôle de l'historien, sinon d'apporter un peu plus d'intelligibilité sur le monde et un surcroît de lucidité à ses concitoyens ? Ni plus ni moins que les autres praticiens des sciences humaines et sociales, mais à sa façon à lui : en historien. [...] Comment produire du recul et du décalage pour obtenir l'équivalent du regard éloigné que l'ethnologue créait en se déplaçant dans l'espace ? (46)

4 Con una prudencia epistemológica muy diferente de lo que se suele reprochar a la objetividad positivista - los excesos de la "crítica del documento" y "el fetichismo del hecho" (Ricoeur 1990 38-39, traducción nuestra) -, Hartog responde que el historiador, sobre todo cuando su campo de estudio es el período contemporáneo, está llamado a desarrollar una "aprensión tan fina y correcta como sea posible sobre las condiciones del 
ejercicio de su oficio" y a "cuestionar la evidencia masiva de lo contemporáneo" (2013 46-47, traducción nuestra). Son estos sentidos del conocimiento histórico, entendido como un modo particular de ver el pasado, los que quisiéramos integrar en esta reflexión, aclarando, no obstante, que en El amigo de Baudelaire, la mirada hacia el siglo XIX es distinta de la que haría un historiador. Lo que nos interesa de las consideraciones de Ricoeur y de Hartog es, puntualmente, la asociación del conocimiento de tipo histórico a una práctica de distanciamiento o de cuestionamiento ("recul", "décalage", "regard éloigné") con respecto a las "evidencias masivas" de lo contemporáneo. Quisiéramos aprovechar este espacio de estudio sobre la presencia del siglo XIX en el siglo XX, para seguir desarrollando las observaciones de Pozzo y de López acerca de El amigo de Baudelaire. Uno de nuestros propósitos es poner de relieve algunas motivaciones del rodeo histórico de la novela de Rivera, que no resultan demasiado visibles si seguimos reduciendo las relaciones entre ficción e historia a un diferendo con la "historiografía tradicional positivista". Otro de nuestros propósitos es mostrar que en esa novela, se condensan los recursos formales que la escritura de Rivera ha ido explorando a lo largo de sus distintas etapas.

5 En la obra de Rivera, la permeabilidad al discurso histórico se afianza en las novelas familiares autobiográficas escritas en los años $70-E l$ verdugo en el umbral (1994) y Nada que perder (1982) - y se acrecienta a partir de los años 80, en las novelas que se adentran en distintos períodos del pasado nacional argentino : el período del rosismo en En esta dulce tierra (1984) y la Revolución de Mayo en La revolución es un sueño eterno (1987). En ambas ficciones, la imaginación del pasado surge de una polaridad temática, autoritarismo-revolución, que viene de los relatos que Rivera escribe en los 60 bajo la influencia del llamado "realismo socialista" (Jiménez 2010 87-105, 249-257). El amigo de Baudelaire comparte varios recursos formales con las dos novelas que la preceden: el monólogo interior, las apariciones intermitentes del diálogo, la configuración fragmentaria del tiempo en el relato y una prosa heterogénea, en la que las repeticiones y las enumeraciones cohabitan con los silencios y los laconismos. Los mismos elementos se encuentran en La sierva (1992), la ficción que retoma el pasado de Bedoya y de su época, pero desde el punto de Lucrecia Basualdo, su empleada y concubina en la sombra.

6 A primera vista, en la novela que nos ocupa, Bedoya es un sujeto con rasgos bastante definidos. Cuando Baudelaire la pregunta en París, durante una cena, "Usted, ¿qué hace además de ser argentino?", él le responde: "Yo soy un burgués. Argentino y porteño, M. Baudelaire" (Rivera 1991 10, 12). En conformidad con los valores de su clase, por ejemplo, el deseo de negar la muerte (Benjamin 129-130), Bedoya está todo el tiempo preocupado por no "vivir las injurias de la vejez" (Rivera 1991 89). Los episodios que cuenta en breves frases sueltas constituyen el relato fragmentario de su progresivo enriquecimiento material : "Compro tierras en Cañuelas" (Id. 15), "Compré a Masha. Pagué, por ella, menos de lo que vale un novillo" (Id. 18), "Vendí a Masha" (Id. 40), "Compro acciones del Ferrocarril Oeste" (Id. 65), "Crece el precio de la tierra. Y el de mis acciones en el ferrocarril" (Id. 72). Detrás de estas frases prosaicas, centradas en las transacciones de mercado, podemos reconocer la representatividad social que el proyecto literario de inspiración realista le exige al personaje. No obstante, a medida que avanzamos en la lectura, nos damos cuenta de que la configuración del personaje rebasa la categoría realista del tipo. Tal como se anuncia en el epígrafe de Ferdinand Céline, "los argentinos no existen", y en el epígrafe de Paul Nizan, "apenas si es un drama burgués”, la clase 
social es sólo una pieza de un engranaje ficcional más complejo, en el que el pasado nacional es sometido al examen crítico de un narrador homodiégético.

7 En varias entrevistas, Rivera (Domínguez 1999 27) ha hablado de lo que su imaginación histórica le debe al hecho de haber vivido "en la Argentina del menemato", es decir, en medio de los desquicios financieros y sociales del capitalismo de fines del siglo XX : "estoy convencido, dice Rivera, de que los representantes de la burguesía argentina que constituyeron este país como nación eran, en general, hombres cultos. Los burgueses que hoy conocemos, los que aparecen en la revista Caras, son personas groseras e incultas" (Russo y Tijman 1996). La declaración del autor da una clave para comprender el punto de vista sobre la historia que asume su narrador. Como suele suceder en las ficciones históricas contemporáneas de América Latina, el mundo ficcional desde el cual se elabora el examen del pasado, es un reflejo, una transposición cualitativa, del presente desde el cual escribe el autor. Bedoya afirma : "la crisis económica : nadie habla, en Buenos Aires, de otra cosa" ; también se refiere a los "hombres prestigiosos que se preguntan qué dirán de la Argentina en los círculos bursátiles y empresariales de Europa" (Rivera 1991 57). Estos enunciados tienen un doble valor referencial: hablan de las evidencias de un presente - finales del siglo XX - que determinan lo que se busca o se reconoce en el pasado - finales del siglo XIX - . Del contraste entre ambas épocas surge el personaje de ese juez en el que se subraya eso que, según Rivera, ha perdido la burguesía a lo largo de más de un siglo de hegemonía, a saber, la cultura letrada. Porque Bedoya es un burgués "culto", es decir, que lee y se apropia deliberadamente de lo escrito por los representantes más ilustres de las letras occidentales: "Séneca, San Agustín, Platón, Voltaire, Maquiavelo" (Id. 61), Edgar Allan Poe, Victor Hugo y Gustave Flaubert. A este último, Bedoya le plagia un fragmento de Madame Bovary, "el encuentro amoroso de Emma y León dentro de un coche tirado por dos caballos, a la luz del sol y en la ciudad de Rouen" (Id. 70). Pero es sobre todo Charles Baudelaire, en su faceta de poeta maldito, quien aparece como una de las figuras en torno a las cuales gravita su pensamiento.

El nombre de Baudelaire es la cifra de un vasto universo de significaciones sobre el cual la pluma de Rivera realiza una selección de motivos para atribuirle una obsesión a su personaje-narrador. En primera instancia, París es el escenario en el que transcurre una historia que va de la Revolución de 1848 a la Comuna. La capital francesa, que en el medio social y político de Bedoya es idealizada como "la ciudad más hermosa del mundo" (74), queda reducida a un decorado nocturno hecho de estereotipos $(10,12,50)$ : el Sena, los cafés, los bares, "la titilante luz de la velas" y las copas de vino. Baudelaire aparece allí como el poeta al que "la Francia burguesa no perdonó que haya gastado treinta y cinco mil francos en un mes" y que un "maldito mes de junio" publicó en París un "maldito libro" - Les Fleurs du mal (1857) - que le costó una condena por ultraje a la moral pública (11). La silueta física del poeta también es trazada con unos pocos rasgos : "su traje negro", sus ojos "pequeños y oscuros", las "líneas crispadas de su mandíbula" y "el envaramiento de su cuerpo". De su biografía familiar, sólo se menciona la relación conflictiva con su padrastro, Aupick, el general de una división parisina. La novela interpreta ese lazo familiar ubicando a Baudelaire en los eventos revolucionarios de 1848 y gritando " $i$ Muera el general Aupick!" y "iviva la revolución!” (77-78). En esta figuración de Baudelaire no faltan los anacronismos, como el hecho de que aparezca como un lector de Ni Dios ni Patrón/Ni dieu ni maître (79), el periódico fundado por el socialista Auguste Blanqui en 1880. 
Dentro de la prolífica historia de lecturas de la obra de Baudelaire, encontramos varios nombres emblemáticos de la literatura francesa del siglo XX : Marcel Proust (1921), Paul Valéry (1928), Jean-Paul Sartre (1946), Georges Bataille (1947) y Maurice Blanchot (1949), entre otros. También está el célebre ensayo "Sur quelques thèmes baudelairiens" de Walter Benjamin (1940). En esta ocasión, para recapitular algunos motivos del universo literario del autor de Les Fleurs du mal y de Le peintre de la vie moderne (Sur Constantin Guys, ca. 1859-1863), además del ensayo de Benjamin, hemos tomado como punto de referencia, la introducción de Georges Blin (1946) y el prefacio de Robert Kopp a una edición, relativamente reciente (2006), de Le Spleen de Paris. En El amigo de Baudelaire, el sistema de alusiones al poeta francés incluye la parodia, los plagios y las citas apócrifas o descontextualizadas. Este Baudelaire es un poeta víctima de los asedios de los valores burgueses (Rivera 1991 51) y un amigo ocasional a quien el joven Bedoya le pagó algunas cenas cuando vivía en París. Una noche, por ejemplo, Baudelaire le dice a Bedoya que le hubiera gustado ser Teresa Cabarrus, "la mujer de Juan Lamberto Tallién", considerada como responsable de la caída y de la decapitación del jacobino Robespierre el 10 de Termidor (Id. 50). En un arrebato de "bufón", Baudelaire "tendido sobre la mesa" se pone a imitar "la vocecita dorada", "la vocecita tan francesa" de Teresa Cabarrus. "Y ahora, dijo Baudelaire, sonriendo, los ojos cerrados, la voz rápida y jadeante, usted, burgués, pague al bufón./ Despierte, Charles, le contesté. Despierte. Usted es sólo una curiosidad que mi presupuesto consiente" (Id. 51). Podríamos decir que esta escena imaginaria en la que un burgués argentino del siglo XIX está conversando con un poeta que viene de ese modelo decimonónico de la civilización que es París, inscribe la novela de Rivera dentro de una tendencia que Cristina Iglesia (2006 36) ha reconocido tanto en la escritura de Sarmiento, como en "toda escritura americana" : el "deseo", "la necesidad de fascinar a los europeos, de cuya fascinación el escritor ha sido, primero, víctima, y la necesidad de humillarlos, porque ha sido, antes, humillado por ellos". La necesidad de humillación de Bedoya lo lleva a decir que "Baudelaire, en Buenos Aires, hubiera sido una puta de lujo. A la que [él] mantendría" (Rivera 1991 64).

La "fascinación" de Bedoya por esa "curiosidad", por ese sujeto tan extraño a su condición social que es Baudelaire, lo lleva a querer apropiarse de su escritura : "quiero creer que fui yo quien me dije que el mal se hace sin esfuerzo, naturalmente, como una fatalidad. Quiero creer que fui yo y no Baudelaire quien dijo esas palabras" (Rivera 1991 37). Para evocar su primer encuentro con Lucrecia Basualdo, la criminal a la que absuelve de un delito y con la que vivirá un amor maldito, es decir, al margen de las normas sociales de su época, Bedoya se apropia de un verso de A une dame creôle: "Podría decir que Baudelaire me la anunció : camina, alta y esbelta, como una cazadora" (Id. 32). "Grande et svelte en marchant comme une chasseresse", dice el verso del poema en francés (Baudelaire 1964 86). Las citas aparecen muy alejadas de su contexto original, como la frase "Tout pour moi devient allégorie" (Rivera 1991 13), sacada de un poema que Baudelaire dedica a Victor Hugo, Le Cygne, y que asocia el tema de la melancolía al tema de la ciudad: "Paris change! mais rien dans ma mélancolie n’a bougé !" (Id. 108). La melancolía - "le goût du néant" (Id. 97), "l'irrésistible Indifférence" (Baudelaire 2006 112) -, el mal que aqueja a aquel que siempre estaría bien allí donde no está - "Il me semble que je serais toujours bien là où je ne suis pas" (Id. 221) -, ese tema que Baudelaire aborda en poemas como Chacun sa chimère, A une heure du matin o N'importe où hors du monde (Le Spleen de Paris ), apenas si tiene un espacio en la vida de Bedoya: la melancolía es sólo un suceso episódico de su ocio. "En los últimos años, cuando la melancolía ocupaba mis ratos de 
ocio, solía pensar en Baudelaire. En las cenas que le pagué. En su cara pequeña y devastada sobre el plato de la cena" (Rivera 1991 49). Sólo en sus ratos de soledad, en los que libra su pulso secreto con el avance hacia la muerte, Bedoya piensa en su "amigo": "cuando estoy solo, nombro, a veces, a Charles. Y digo : a tu salud, mi querido Charles, y vacío la copa" (Id. 61).

Pero sobre todo, en ese otro imaginario que es Baudelaire, Bedoya presupone la actitud despectiva de Europa hacia ese territorio desconocido que es América, y concretamente, la Argentina: "¿Qué es Buenos Aires? ¿Una aldea de Francia en un largo crepúsculo de carnaval ?". Para este Baudelaire, la capital argentina es un sitio que no merece un viaje porque tiene la misma "tiranía de la cara humana" (Id. 65) que reina en todas partes, Francia incluida. En el monólogo de Bedoya, Baudelaire irá afianzándose como la figura de una alteridad imaginaria que motiva las preguntas que el juez se hace sobre su propio país. A propósito de su relación con Lucrecia, una relación en la que el poder mortífero del erotismo se anuda con la jerarquía socioeconómica heredada de la época colonial, Bedoya se pregunta : “Conoció Charles, estos códigos criollos de la perversidad ?” (Id. 39). Rivera (Russo y Tijman 1996) se ha referido a la génesis del mundo ficcional de su novela. Al parecer, el punto de partida fue un crimen que "encontró", sin precisar la fuente, en la época en que la Argentina "se constituye como nación". "Después la novela comenzó a armarse", dice el autor. En la novela, ese crimen es evocado dentro de la crónica judicial de un periódico decimonónico, El Orden (Rivera 1991 20-21, 27), y corresponde al homicidio de Genaro Negretti, un retratista "gringo" que era propietario de una chacra. Para quedarse con esta chacra, Lucrecia, que era su hijastra, decide asesinarlo con la complicidad de dos hermanos gauchos : el menor, Pedro Vera, es un retrasado mental que asume la autoría del crimen ; el mayor, Ramón Vera, es un veterano "que conoce las levas militares, los fortines de frontera y que participó del sitio de Montevideo [...] y del asalto a las fortificaciones paraguayas" (Id. 28). Al igual que su amigo Ricardo Piglia, quien por los mismos años publica La ciudad ausente (1992), Rivera es un lector asiduo del género negro y un admirador de Raymond Chandler (Iglesia 2002). En su opinión, "las buenas [novelas policíacas] dan el perfil de una sociedad" (Rodríguez 2003). En la novela, esta inspiración en el género negro queda consignada cuando Bedoya recuerda a Edgar Allan Poe, después de que mata con un disparo a Ramón Vera, el gaucho que había osado retarlo con un cuchillo, en su propia oficina (Rivera 1991 64). El perfil de la sociedad decimonónica que "se arma" a partir del crimen del propietario de la chacra remite entonces a las tensiones entre el gringo, el gaucho y el burgués del mundo civilizado. Según Pozzo (40), el gaucho Ramón Vera "es la carne de cañón que se "usa" para construir la zanja de Alsina o para la campaña de Roca al desierto", el hombre que "ha dejado de formar parte del cuerpo ciudadano para pasar al exilio de los 'desterritorializados' que pierden su condición humana" (41). La obsesión de Bedoya por Baudelaire, ese escritor francés para quien Buenos Aires no pasa de ser "una aldea de Francia", es entonces complementaria de una lectura del pasado nacional argentino a la luz de la dicotomía civilización y barbarie. Dicho de otro modo, en la perspectiva de Bedoya, Baudelaire es un pretexto para cuestionar esos dos valores en los cuales su país ha traducido la búsqueda del progreso. De ahí su obsesión por Sarmiento : esa figura en la que confluyen el hombre de letras y el hombre de estado, el "autor" que asienta por escrito la célebre dicotomía en la que se sostiene el ideal republicano de la nación (Kirkpatrick y Masiello 8). De ahí también las referencias a Juan Manuel de Rosas, considerado con uno de los principales responsables del baño de sangre que la unidad republicana habría intentado detener. 
Como en el caso de Baudelaire y de la historia francesa, las alusiones al pasado nacional argentino casi siempre se mantienen en el ámbito de los saberes compartidos no especializados. Son referencias de índole general, en las que nunca prima el despliegue erudito del trabajo con las fuentes, sino al contrario, los sentidos depositados en la cifra mínima de los estereotipos. Rivera afirma (Domínguez 27) que "cuando abordó En esta dulce tierra o El amigo de Baudelaire, prescindió de toda lectura histórica". En este tipo de ficcionalización de la historia, la parodia humorística juega un papel decisivo. Así, en un gesto crítico común en la literatura argentina y latinoamericana de los 90 (Kirkpatrick y Masiello 2), Sarmiento es presentado bajo diferentes facetas que desacralizan su figura de artífice del progreso. Aparece como un "admirador incondicional de la democracia norteamericana, que desea implantarla en estos pagos afligidos por la indolencia española" (Rivera 1991 15) ; como un provinciano advenedizo y acomplejado, que "habla mucho del dinero porque nunca lo tuvo" (Id. 34); como un tacaño maniático que "anota escrupulosamente cuánto le costaron sus "orgías"” (Ibid.) ; como el enamorado "frustrado" (Id. 68) de Aurora Vélez Sarsfield; y también, como un "viejo que cruza el silencioso espanto de la ciudad apestada con sus botas polvorientas" (Id. 47). De acuerdo con el mismo registro paródico, Rosas aparece como un gaucho "que escribe, en su exilio británico, cartas de chismoso, y enseña, a los farmers, las delicias del mate" (Ibid.). Con respecto a esta figura histórica, hay que decir que Rivera la había retomado en su novela En esa dulce tierra, en ese momento "catártico", como dice Tulio Halperín (1987 74-77), en el que a través de la "imagen [del terror rosista] podían expresar[se] de un modo metafórico [los] sentimientos frente al terrorismo de Estado impuesto entre 1976 y 1983". Rivera seguirá desarrollando la figuración de Rosas en dos novelas posteriores : El farmer (1996) y Ese manco Paz (2003) (Cf. Waldegaray 2008). En la época evocada en El amigo de Baudelaire, Rosas está viviendo su exilio en Gran Bretaña y no ocupa un lugar central dentro del mundo ficcional. Para Bedoya, el castigo ejemplar que el dictador aplica a Camila O'Gorman y al cura Ladislao Gutiérrez por el escándalo de sus amores es ya un recuerdo lejano: “[El señor Enrique O'Gorman, nombrado jefe de policía por el señor Samiento], no puede creer que tuvo una hermana llamada Camila, a la que se acusó de compartir los extravíos sexuales de un curita libidinoso" (Rivera 1991 33). Lo que sí hace la novela es imputar a Rosas el proceso de concentración de las tierras. Y para esto utiliza un recurso frecuente en la prosa del autor: la enumeración de nombres propios que, agrupados en una serie, buscan representar un grupo hegemónico, en este caso, la Sociedad Rural Argentina. Este desarrollo del relato, entra en resonancia con los comentarios y las preguntas que Bedoya le hace a Baudelaire en su imaginación: "Me gusta el olor a campo, Charles. Contemplo, durante largos, largos minutos, montado a caballo, miles de ovejas, como un mar gris, inmóvil. [...] ¿Sabe, Charles, cuál es el verdadero olor de la pampa ? Yo, sí : el del dinero" (Id. 13). Sobre don Francisco Madero, Bedoya dice que a través del "relato seco y lacónico de ese viejo unitario" podía revivir el terror impartido por los federales, "la furia salvaje de los perseguidores, la sombra del degüello esparcida sobre las sombras en fuga, y el miedo y la locura que vejaban a las sombras en fuga" (Id. 20). Sin embargo, como para señalar las paradojas de la historia, Bedoya agrega que "don Francisco Madero es, hoy, un próspero latifundista", como lo es también don José Martínez de Hoz, quien, en 1851, "participó de un minué ofrecido a la señorita hija del dictador Juan Manuel de Rosas" (Ibid.). Y Bedoya concluye: "Las decapitaciones nos civilizaron lentamente". En el transfondo del antagonismo entre Rosas y Sarmiento, y de la oposición entre barbarie y civilización, la frase es un retruécano que señala una ironía de la historia : en las manos de un sector de la sociedad, ha quedado 
concentrado un poder, gracias a la acción de otro sector que fue su rival a muerte. Y así como en este retruécano Rosas es el agente de cierta civilización, en el resto de la novela, Sarmiento se convierte en el agente de cierta barbarie.

Si hay algo que permita situar a El amigo de Baudelaire como una narrativa del XIX en el $\mathrm{XX}$, es el empeño de Bedoya en mostrar todo lo que implica la delimitación de la patria como territorio civilizado, es decir, la violencia política y la guerra. Esta es la perspectiva desde la cual se traza el perfil de Sarmiento. Bedoya no pretende descubrir nada nuevo sobre el presidente : ¿Qué se puede decir del señor Sarmiento que no se haya dicho ya ?" (Id. 34). Sin embargo, no puede dejar de preguntarse "¿Quién es el señor Sarmiento? ¿Dónde acaba el señor Sarmiento? (Id. 35)". En las letras argentinas (Cf. Iglesia 2002101 y Sarlo 2006 1-2), la palabra "enigma" suele ser asociada con el autoritarismo y, con frencuencia, surge en las alusiones al rosismo o al Proceso de Reorganización Nacional. A través de esas preguntas la ficción de Rivera translada el enigma hacia donde estamos menos acostumbrados a situarlo, es decir, hacia la figura de Sarmiento y el mundo de la supuesta civilización. Bedoya dice que "se tropieza con más generales que batallas". Un día se cruza en un baño con José María Arredondo, uno de los miembros del Estado Mayor de Sarmiento; ese día, mientras escucha "cómo las tropas nacionales al mando de Arredondo y de Sandes derrotaron a los paisanos que seguían a Angel Vicente Peñaloza, El Chacho" (Rivera 1991 22), Bedoya retiene una fotografía de los hombres de Peñaloza derrotados en Caucete; su mirada se detiene en las "caras aindiadas", en los "calzones desgarrados", en "las marcas de los azotes, de las apaleaduras, de las heridas abiertas" (Id. 23). Cuando Bedoya menciona a Lucio V. Mansilla, otro militar de la civilización que se ha enemistado con el presidente Sarmiento y que se ha dado el lujo de hacer el viaje que éste nunca haría, "La excursión a los indios ranqueles" (Iglesia 2002 79), aprovecha esta alusión para recordar que el presidente Sarmiento "se arroga el deber (y aun el derecho) de matar gauchos, para que su deseo se cumpla" (Rivera 1991 15, 67). Después, cuando Bedoya cumple sesenta años, ya estamos en las cercanías del año 1880. Lo sabemos porque brinda su apoyo al candidato presidencial Julio A. Roca, "uno de los oficiales más jóvenes [y más cultos] del Ejército" (Id. 69), "un caballero" que "derrotó al general Arredondo en la batalla de Santa Rosa" (Id. 74). Es también la época de la presidencia de Nicolás Avellaneda y de su ministro de guerra, Adolfo Alsina. Desde la misma perspectiva que insiste en la exclusión y la violencia política como elementos inherentes al proyecto republicano, Bedoya habla de "la zanja que ordenó abrir el doctor Alsina, y que, dicen, detendrá las depredaciones del malón en tierras de la provincia de Buenos Aires" (Id. 32). El conjunto de nombres y de episodios históricos a los cuales alude Bedoya de manera dispersa y fragmentaria, sin someterlos a una organización cronológica, obedece sin embargo a una lógica temática, es decir, a una selección que lleva implícito un modo de entender la historia. El amigo de Baudelaire parece decir que la barbarie, el desquicio de la violencia, no sólo aparece en "la estancia" sino también en "república".

Esta reescritura sobre el pasado, en la cual las diferencias se transtocan y los opuestos terminan convirtiéndose en lo mismo, tiene que ver con una concepción general del proceso histórico que recorre las novelas de Rivera y que en La revolución es un sueño eterno se hace explícita a través de la voz de Juan José Castelli, el orador de la Revolución de Mayo (Jiménez 2010 239-248). Es la visión de la historia como un teatro, un "escenario" "cruzado por hombres que encarnan papeles" (Rivera 1987 26) y en el que "se trocan las máscaras en la representación” (Id. 99). “QQué es el señor Rivadavia, se pregunta Castelli, si no el nombre con el que Alzaga retorna al escenario ?" (Ibid.). En este punto, la pluma 
de Rivera abandona el enfoque centrado en las particularidades de cada época, para adentrarse en una problemática más abstracta, que sería la cuestión de la identidad. Ya hemos visto el ejemplo en el que, Baudelaire, tendido en la mesa de un bar de París, adopta "la saltarina vocecita", "la vocecita dorada" (Rivera 1991 50) de Teresa Cabarrus, la persona que a él le hubiera gustado ser. A través del plagio, Bedoya se convierte en Flaubert, ese otro escritor francés que lo asedia en su mente: "yo vivo en Croisset, y escribí: El burgués es el animal que nada entiende del alma humana" (Id. 72). También se convierte en Sarmiento. Visualizándolo como un paseante de Buenos Aires, dice : "soy yo ese hombre viejo que pisa la ciudad apestada y vacía ?" (Id. 47). En el romance maldito de Lucrecia y Bedoya, las ganas de ser el otro quedan plenamente significadas en el episodio en que, frente a un espejo, la empleada se pone un antifaz que el juez le ha regalado y que probablemente alguna "patrona" perdió en una fiesta de disfraces. Hay que tener presente que Lucrecia quiere ser una de esas "patronas". "Con el antifaz sobre los ojos, la cara contra el espejo", Lucrecia le pregunta a Bedoya si a veces no desea ser ella: "le pregunto quién sería ella, si yo deseara, en algún momento, ser ella. Ella responde que yo" (Id. 64). En Rivera, aunque el proceso histórico sea abordado a partir de oposiciones binarias, la ficción siempre termina sondeando ese territorio en el que se acercan los pares aparentemente contradictorios. Los sujetos se transforman y terminan por impregnarse de las características de una alteridad que los fascina y de la que quieren, sin embargo, distinguirse. ¿Qué comparten un burgués y un poeta, o un patrón y su empleada ?, ¿cuál es la zona en la que los artífices de la civilización se encuentran con los demonios de la barbarie ? Las preguntas de este tipo también operan en la imaginación histórica de El amigo de Baudelaire. Y por esta vía, la prosa de Rivera empieza a adentrarse en ese "desafío al principio de contradicción", en esa "enunciación de la identidad de los contrarios" a la que Octavio Paz (99) se refiere para definir ese "escándalo" que introducen las imágenes de la poesía.

Entre las múltiples distinciones que disuelve El amigo de Baudelaire, hay una en la que quisiéramos detenernos para terminar nuestra lectura : la relativa a la categorización de los discursos. En el texto, son frecuentes las preguntas y los comentarios metaliterarios sobre la "lírica", la "novela", el "poeta" y el "novelista". A través de los autores del siglo XIX - Baudelaire, Flaubert, Victor Hugo -, la literatura francesa sigue funcionando como esa alteridad que le permite a Bedoya plantearse el enigma de Sarmiento, esta vez en su faceta de escritor y de "autor de una nación" (Kirkpatrick y Masiello 1994). Con tono soberbio, Bedoya piensa : "El señor Domingo Faustino Sarmiento no conoce la lírica. Y los Estados Unidos, tampoco. ¿Y yo ? Yo conocí París. Y a Charles, su flâneur” (15). Para el juez burgués, que empieza su monólogo interrogándose sobre la ética de la escritura autobiográfica, Sarmiento no pasa de ser el mero practicante de una prosa al servicio de un utilitarismo maniático, un "señor que anota escrupulosamente cuánto le costaron sus 'orgías”' (34), tal como lo hemos indicado antes. Y Bedoya se pregunta : “Por qué el señor Sarmiento es el escritor que es ?/Puedo saber de dónde viene la grandeza de Baudelaire. La de Flaubert. Y la de Hugo (a quien la Francia de los pobres y humillados puso de pie)./ Pero la del señor Sarmiento, ¿de dónde ?" (89) Y para bordear este otro enigma, la ficción de Rivera despliega un lenguaje que toma su impulso en la fusión entre la poesía y la prosa :

Piedras esparcidas por un ciego en calles largas y estrechas: la ciudad es eso. Piedras que hieden silenciosas bajo un sol de desierto. Puertas y ventanas cerradas en las casas silenciosas y negras bajo la luz de un sol de desierto. La ciudad es eso. 
Nadie en las calles, salvo el señor Sarmiento que camina, sombra adusta y

deformada, bajo un sol de desierto, por las calles vacías de la ciudad (44).

17 Los sintagmas nominales, el ritmo pautado por las anáforas, la repetición de frases "piedras", "sol de desierto", "la ciudad es eso" - confieren al fragmento la apariencia de una prosa poética. Estos giros del estilo de Rivera siempre han retenido la atención de la crítica (Cf. Rabat 2000). Dice Rivera (Domínguez 28) que este "desarrollo reiterativo" de su estilo "surgió con La revolución es un sueño eterno" y "reaparece" en En esta dulce tierra y en las novelas posteriores. No obstante, cuando consideramos detenidamente la diacronía de su escritura, observamos que lo que el autor define como un "surgimiento" es en realidad el retorno de algunas posibilidades poéticas que había explorado décadas atrás. En ese fragmento, además del estilo reiterativo, se despliega un imaginario de la desaparición y de lo espectral a través de frases como "nadie en la ciudad", "casas silenciosas y negras" y "calles vacías". Para decirlo con las palabras de Paz (68-69), la escritura de Rivera renuncia aquí a la "crítica" y al "análisis" que caracterizan el "avance" de la prosa, y en cambio, dilata el texto con los recursos propios de la poesía : el ritmo, entendido como un "imán" que "convoca las palabras" (53), y la libertad asociativa suscitada por las correspondencias y las analogías.

18 En El amigo de Baudelaire, el tema baudelairiano de la ciudad es, de manera evidente, uno de los principales motores de la imaginación histórica. Sabemos que hacia 1859, luego de la primera edición de Les Fleurs du mal, "la ciudad [París] acaparó la inspiración de Baudelaire" (Blin 32, traducción nuestra) y que Le Spleen de Paris surge en buena medida del "vínculo interno" entre "la imagen del choc y el contacto con las masas que habitan las grandes ciudades" (Benjamin 344, traducción nuestra). No obstante, mientras que en Baudelaire la ciudad es un espacio de concurrencia - como dice Benjamin, "la inmensa multitud de los transeúntes, el público de la calle" - , en Rivera, por el contrario, la ciudad es un lugar cuyo signo es la ausencia, tal como se anuncia también en el título de la novela negra de Piglia, La ciudad ausente. Como lo vemos en las imágenes antes mencionadas - "nadie en la ciudad", "casas silenciosas y negras", “calles vacías" -, en El amigo de Baudelaire, la ciudad, Buenos Aires, se metaforiza como un lugar de lo que ya no está, un sitio que ha sido despojado de los cuerpos que lo habitaban. Se trata de una Buenos Aires que aunque "opulenta”, es "hipócrita, miserable" (16), una Buenos Aires muy opuesta a aquella que Sarmiento había dignificado como "señora de la navegación de cien ríos que fluyen a sus pies" y que "estaba llamada a ser un día la ciudad más gigantesca de ambas Américas" (Sarmiento 59). En el poema en prosa Les Foules, Baudelaire (2006 127) establece una unidad indisoluble entre la muchedumbre ("multitude") y la soledad ("solitude"): "Le promeneur solitaire et pensif tire une singulière ivresse de cette universelle communion". Sarmiento es también una especie de paseante solitario ("promeneur solitaire") pero su comunión no es con la muchedumbre sino con un espacio que acaba de ser sumido en la nada. A la manera de un poema simbolista, el personaje histórico entra en correspondencia con ese entorno de fantasmas. Sarmiento, el flâneur de las calles vacías de Buenos Aires, se confunde con ese espacio espectral hasta convertirse en una "sombra adusta y deformada".

19 Momentos poéticos de ese tipo abundan en las obras que Rivera publica en los años 60, por ejemplo, en Cita (1965). Los cuentos de este volumen subrayan también la interacción entre el mundo interior y el mundo exterior a través de un registro de la percepción (Jiménez 2009 107-109). Además, en ellos ya está presente el imaginario del frío, del invierno y de la lluvia que impregnará a las ficciones históricas posteriores. En 
"Alejandro", un relato sobre la iniciación sexual de un adolescente, se cuenta lo que éste mira desde un tren durante un viaje con su padre: "Claudio, atenaceado por el frío, miraba a través de la ventanilla extenderse al país en un quebrado paisaje yermo, bajo una claridad de hielo. Caras sin sonrisas. Caballos atados a postes de telégrafos. Perros terrosos. [...] La dilatada tierra de los argentinos" (40). En "Cita", el cuento que da el título al volumen, cuyo tema es una reunión entre los delegados sindicalistas de una provincia, también se evocan las percepciones de un sujeto sobre un espacio exterior poblado por signos de la devastación; ese afuera de la ausencia que ve el delegado Miguel Sepúlveda es "la llanura, muda bajo la mirada implacable de un cielo de invierno, [...] envuelta, como un planeta muerto, en la espejeante niebla de una noche sin sonido" (21). Más de dos décadas después, apaciguados los dilemas sobre la literatura y la revolución, y luego de haber explorado el vínculo entre memoria e historia política en las novelas que se inspiran en la autobiografía familiar, la escritura de Rivera libera con mayor decisión esas posibilidades poéticas que habían quedado un poco sumergidas bajo la finalidad didáctica de la llamada prosa realista. Y es precisamente en el momento en que la dictadura empieza a formar parte del ayer y en el que hay mayor espacio para considerar los desmanes de la alianza - formulada en el siglo XIX - entre república y progreso capitalista, es justamente en ese presente de los años 90, que la pluma de Rivera desplaza el centro de interés hacia Sarmiento, generando figuraciones poéticas como la siguiente :

¿Quién es ese viejo que cruza el silencioso espanto de la ciudad apestada con sus botas polvorientas, como si la ciudad y su apestado silencio, su podredumbre, las emanaciones de la pudrición de los muertos y de los que mueren, y de los que huyen, y las piedras y los muros que sobrevivirán a la peste, fueran suyos ? (Rivera 1991 47)

En enero del 2013, en el marco del coloquio internacional Littérature et Histoire en débats, Eric Mélouchan presentó una ponencia cuyo título era "Les sentiments du passé". Uno de sus propósitos era aclarar el viejo malentendido según el cual el conocimiento del pasado depende de una racionalidad insensible : "l'historien, afirmaba Mélouchan, se sent touché par le passé"; "ses enjeux de connaissance impliquent une sensibilité à quelque chose qui a disparu et qui a laissé des restes". Y específicamente, con respecto a la historia de la literatura, tal vez intentando proponer una alternativa distinta al relato centrado en la figura del padre y en la angustiosa necesidad de matarlo, hablaba de la necesidad de tener en cuenta los lazos de amistad, "le sentiment politique d'alliance". Evocaba a Madame de Staël, que se refería a Rousseau como a un amigo, y recordaba que hay algo del sentimiento de la amistad en el modo en que un lector escoge a sus autores ("on choisit ses auteurs comme on choisit ses amis"). Los amigos literarios de Rivera son numerosos y, para los propósitos de nuestra lectura, bastaría con mencionar a unos pocos a quienes ha tomado en préstamo algunas herramientas de trabajo: a Faulkner y Joyce, el monólogo interior ; a Borges, "la manera de adjetivar"; a Arlt, algo que podríamos situar dentro del registro de lo maldito y que él llama "la ausencia de compasión con el personaje" (Jiménez 2010 317). En Baudelaire, Rivera encuentra el modelo de un cuestionamiento radical hacia los valores de la burguesía, esa clase cuyo último eslabón sería el círculo de burgueses "bárbaros e iletrados" de la Argentina del menemato. Pero sobre todo, Rivera parece haberse reconocido en el propósito ambicioso ("ambicieux") del que Baudelaire le habla a Arsène Houssaye en la carta que introduce a Le Spleen de Paris : "rêve[r] le miracle d'une prose poétique, musicale sans rythme et sans rime, assez souple et assez heurtée pour s'adapter aux mouvements lyriques de l'âme" (104). En Baudelaire, tomado como el escritor que inocula a la prosa con la poesía, el escritor argentino encuentra un amigo, es 
decir, una complicidad de otro tiempo que le sirve como punto de apoyo para problematizar las narrativas del progreso que definen lo nacional. Se produce entonces ese distanciamiento, inherente a la inteligibilidad histórica, que consiste en poner en perspectiva lo que parece familiar. En este caso, la ficción se vuelve histórica, no tanto porque revele algo desconocido sobre el pasado, como lo hemos visto aquí en el caso de Sarmiento, ni porque "subjetice" lo que "insensiblemente objetivado" por los historiadores. La ficción adquiere un carácter histórico porque mediante la fusión de la prosa con la imaginación poética, transforma en enigma algunas significaciones cristalizadas en torno al pasado nacional y encuentra un intersticio discursivo propio para nombrar la alteridad de ese pasado.

\section{BIBLIOGRAFÍA}

Bibliografía

Baudelaire, Charles. Le Spleen de Paris. Petits Poèmes en prose, ed. Robert Kopp. Paris : Gallimard, 2006.

Benjamin, Walter. “Le conteur. Réflexions sur l'oeuvre de Nicolas Leskov”. 1936. Cuuvres. Tome III, tr. Pierre Rusch. Paris : Gallimard, 2000. 329-390.

Benjamin, Walter. "Sur quelques thèmes baudelairiens". 1940. Oeuvres. Tome III, tr. Maurice de Gandillac y Rainer Rochlitz. Paris : Gallimard, 2000. 329-390.

Blin, Georges. "Introduction”. 1948. Le Spleen de Paris. Petits Poèmes en prose, ed. Robert Kopp. Paris : Gallimard, 2006. 7-41.

Halperín Donghi, Tulio. "El presente transforma el pasado : el impacto del reciente terror". Ficción y política. La narrativa argentina durante el proceso militar. Buenos Aires : Alianza estudio, 1987. 71-95.

Hartog, François. Régimes d'historicité. Présentisme et expériences du temps. 2003. Paris : Seuil, 2012.

Hartog, François. Croire en l'histoire. Paris : Flammarion, 2013.

Iglesia, Cristina. La violencia del azar. Ensayo sobre literatura argentina. Buenos Aires : Fondo de Cultura Económica, 2002.

Iglesia, Cristina. "El escritor americano", Cahiers de LIRICO 1, ed. Julio Premat (2006) : 35-37.

Jiménez, Iván. “Andrés Rivera. Du réalisme révolutionnaire à la subjectivation de l'histoire”. Les littératures d'Amérique latine au XXe siècle : une poétique de la transgression ?, dir. Laurent Aubagne, Jean Franco et Alba Lara-Alengrin. Paris : l'Harmattan, 2009. 99-118.

Jiménez, Iván. Subjectivité et fiction historique dans l'oeuvre de Andrés Rivera. Tesis doctoral. SaintDenis: Université Paris 8, 2010.

Kirkpatrick, Gwen and Masiello, Francine (eds.). "Introduction: Sarmiento between History and Fiction". Sarmiento. Author of a Nation. Berkeley-Los Angeles-London: University of California Press, 1994. 1-16. 
Kohan, Martín. "La humanización de San Martín : notas sobre un malentendido", Revista Iberoamericana 213. Héroes de papel : avatares de una construcción imaginaria en América Latina, dir. Mabel Moraña (2005) : 1083-1096.

López de Espinosa, Susana. “Configuración de Sarmiento y Charles Baudelaire en El amigo de Baudelaire”, Hipótesis y discusiones 9. Andrés Rivera, utopismo y revolución. (1996) : 47-56.

Paz, Octavio. El arco y la lira. México : Fondo de Cultura Económica, 1956.

Pozzo, Cecilia. "El amigo de Baudelaire y La sierva. Trabajar con la memoria”, Hipótesis y discusiones 9. Andrés Rivera, utopismo y revolución. (1996) : 31-46.

Rabat, Marina. "Una entrevista a Andrés Rivera : ‘Un estilo propio habla de la experiencia histórica' ", Razón y revolución 6 (2000). Disponible en :

www.elortiba.org/pdf/rabat_rivera.pdf

Ricoeur, Paul. “Objectivité et subjectivité en histoire”. Histoire et vérité. 1955. Paris : Seuil, 1990. 27-50.

Ricoeur, Paul. "La fonction narrative". La narrativité, dir. Dorian Tiffeneau. Paris : CNRS-Centre Régional de Publication de Paris, 1980. 49-67.

Rivera, Andrés. Cita. Buenos Aires : Ediciones La rosa blindada, 1965.

Rivera, Andrés, Miguel Russo y Gabriela Tijman. “Andrés Rivera ” (Entrevista). La Maga (1996).

Disponible en : www.literatura.org/Rivera/arrepo/html

Rivera, Andrés. La revolución es un sueño eterno. 1987. Madrid : Punto de lectura, 2001.

Rivera, Andrés. El amigo de Baudelaire. Buenos Aires : Alfaguara, 1991.

Rivera, Andrés y Domínguez, Carlos. "El tejedor de la trama y la crueldad” (Entrevista). El compás de oro. Buenos Aires : Desde la gente (Ediciones Instituto Movilizador de Fondos Cooperativos), 1999. 23-29.

Rivera, Andrés y Rodríguez Marcos, Javier. "Toda escritura es provisional " (Entrevista). Babelia. El País. 1 feb. 2003.

Sarlo, Beatriz. “Sujetos y tecnologías. La novela después de la historia”, Punto de vista 86 (2006) : $1-6$.

Sarmiento, Domingo Faustino. Facundo, ed. Roberto Yahni. Madrid: Cátedra, 1990.

Waldegaray, Marta. “Andrés Rivera : mito romántico y desencanto político en la figura de Juan Manuel de Rosas", Les sujets contemporains et leurs mythes en Espagne et en Amérique latine. Ed. María Llombart, Perla Petrich y Julio Premat. Alacant-Saint-Denis : Universitat d'Alacant y Université Paris 8, 2008. Disponible en : www.cervantesvirtual.com/FichaObra.html ?Ref =30219

\section{NOTAS}

1. “[...] la subjectivité mise en jeu n'est pas une subjectivité quelconque, mais précisément la subjectivité de l'historien : le jugement d'importance, - le complexe de schèmes de causalité, - le transfert dans un autre présent imaginé, - la sympathie pour d'autres hommes, pour d'autres valeurs, et finalement cette capacité de rencontrer un autrui de jadis, - tout cela confère à la subjectivité de l'historien une plus grande richesse d'harmoniques que n'en comporte par exemple la subjectivité du physicien. Mais cette subjectivité n'est pas pour autant une subjectivité à la dérive" (Ricoeur 1965 38). 
2. "L'objectivité ici doit être prise en son sens épistémologique strict: est objectif ce que la pensée méthodique a élaboré, mis en ordre, compris et ce qu'elle peut ainsi faire comprendre" (Ricoeur 1965 27). Y más adelante : “[Marc Bloch] a mille fois raison de nier que l'historien ait pour tâche de restituer les choses 'telles qu'elles se sont passées'. L'histoire n'a pas pour ambition de faire revivre, mais de re-composer, de re-constituer, c'est-à-dire de composer, de constituer un enchaînement rétrospectif. L'objectivité de l'histoire consiste précisément dans ce renoncement à coïncider, à revivre, dans cette ambition d'élaborer des enchaînements de faits au niveau d'une intelligence historienne" (Id. 30).

3. “On voit ainsi à l'oeuvre, dans ce qu'on vient d'appeler l'intérêt pour la communication qui règle même l'attitude objective de l'histoire, une dialectique entre l'étranger et le familier, entre le lointain et le proche. C'est cette dialectique qui place l'histoire dans le voisinage de la fiction, parce que la reconnaissance des valeurs du passé dans leur différence ouvre le réel au possible. L'histoire elle aussi, à cet égard, appartient à la logique des possibles narratifs. Mais elle ne le fait pas par le moyen de la fiction, mais précisément par le moyen de ses histoires 'vraies'. Les histoires 'vraies' du passé libèrent les potentialités du présent. Croce aimait dire qu'il n'y a d'histoire que du présent. C'est là sans doute du paradoxe. Mais il est plein de sens. Il suggère que l'histoire est le champ des 'variations imaginatives' qui environnent le réel, tel qu'il est tenu pour allant de soi dans la vie quotidienne" (Ricoeur 1980 67).

4. Coloquio internacional realizado entre el 10 y el 12 de enero de 2013. Comité de organización : Lucie Campos (Paris 8/Collège de France), Catherine Coquio (Paris 8/Paris 7 Diderot), Assia Kovriguina (Paris 8), Annick Louis (EHESS). Éric Mélouchan presentó su ponencia el sábado 12 de enero de 2013 en la nueva sede los Archivos Nacionales (Saint-Denis).

\section{RESÚMENES}

El amigo de Baudelaire fue escrito durante el gobierno de Ménem, cuando la dictadura militar de 1976-1983 empieza a formar parte del ayer. La novela invierte los sentidos habituales de la dicotomía "civilización y barbarie" ; mediante un imaginario de la ausencia, asocia el "enigma" de la historia, no con el rosismo, sino con la figura emblemática y contradictoria de Sarmiento, el "autor de una nación". Baudelaire, el escritor que inocula a la prosa con la poesía, aparece como un amigo, es decir, como una alteridad imaginaria que le ofrece a Rivera - y a su narrador, el juez Bedoya - un apoyo para problematizar las narrativas del progreso que definen lo nacional. La prosa poética hace que la ficción se vuelva histórica, no porque introduzca subjetividad allí donde, supuestamente, los historiadores han instaurado la objetividad, sino porque cuestiona e introduce una distancia con respecto a ciertas lecturas cristalizadas del pasado nacional.

El amigo de Baudelaire a été écrit dans pendant les années 90, au moment où la dictature militaire de 1976-1983 commence à être considérée comme faisant partie du passé. Le roman inverse les sens habituels de la dichotomie "civilisation et barbarie"; au moyen d'une poétique de l'absence, il relie l' "énigme" de l'histoire, non au régime de Rosas (el rosismo), mais à la figure contradictoire et emblématique de Sarmiento, l'“auteur d'une nation". Baudelaire, l'auteur qui inocule la poésie à la prose, appararaît comme un ami, c'est-à-dire comme une altérité imaginaire qui offre à Rivera - et à son narrateur, le juge Bedoya - un point d'appui pour problématiser les récits de la naissance de l'état-nation. La prose poétique fait que la fiction devienne historique, non parce qu'elle fasse émerger la subjectivité que les historiens sont censés avoir négligé au 
profit de l'objectivité, mais parce qu'elle remet en question et prend distance de certaines lectures figées du passé national.

El amigo de Baudelaire was written during Menem's government, as the 1976-1983 military dictatorship starts being considered as part of the past. The novel reverses some usual senses of the dichotomy "civilization and barbarism"; by means of a poetics of the absence, it connects the "mystery" of history, not to the tyranny of Rosas (el rosismo) but to the emblematic and contradictory figure of Sarmiento, the "author of a nation". Baudelaire, the writer who infuses prose with poetry, appears as a friend, i. e. an imaginary otherness that gives Rivera - and his narrator, judge Bedoya - a support to criticize the histories of the building of the nation. Poetic prose makes fiction become historic, not because of the involvement of the subjectivity that historians are supposed to replace with objectivity, but because it brings into question and moves away from some stablished ways of reading Argentine national past.

\section{ÍNDICE}

Mots-clés: fiction, histoire, subjectivité, Baudelaire, Sarmiento

Palabras claves: ficción, historia, prosa poética, subjetividad

Keywords: history, poetic prose, subjectivity

\section{AUTOR}

IVÁN JIMÉNEZ

UPEC 